\title{
Analyses of the Spatial Pattern of Drought Risk in Tigray Region, Northern Ethiopia
}

\author{
1, 2, *TEFERA, AS; ${ }^{3}$ AYOADE, JO; ${ }^{4}$ BELLO, NJ \\ ${ }^{I}$ Pan African University, Life and Earth Sciences (including Health and Agriculture) Institute, University of Ibadan, Ibadan, Nigeria \\ ${ }^{2}$ College of Agriculture and Environmental Science, Adigrat University, Adigrat, Ethiopia \\ ${ }^{3}$ Department of Geography, University of Ibadan, Ibadan, Nigeria \\ ${ }^{4}$ Federal University of Agriculture, Abeokuta, Nigeria \\ *Corresponding Author Email: c.amaresisay@gmail.com (ORCID: 0000-0002-3248-755X)
}

\begin{abstract}
Drought risk index uses the meteorological drought hazard index and the socioeconomic drought vulnerability aspects to assess the level of drought risk in an area. This study examined the extent and spatial pattern of drought risk in, Tigray region, one of the recurrently drought-affected areas in Ethiopia. Monthly Gridded Climatic Research Unit (CRU) Time-series (TS) data version 4.01 data on twelve selected stations, was used to calculate the Standard Precipitation and Evapotranspiration Index (SPEI). Additionally, socioeconomic data collected from various sources were also used to assess drought vulnerability. Drought risk levels of each district were, then calculated based on the drought hazard and drought vulnerability indices. The results indicated that about $44.1 \%$ of districts were categorized under high to very high drought risk levels. However, the test of variation, using one-way ANOVA, has shown no significant variation in drought risk between districts at $\mathrm{p}<0.05$. The results of spatial autocorrelation test also indicated the presence of clustered pattern of drought risk. The study has also revealed high and very high drought risk levels largely clustered in the western, eastern and southern zones of the study area. Overall, the study has demonstrated the importance of integrating socioeconomic and climate data for comprehensive drought risk characterization, which can be used as an input for drought management planning.
\end{abstract}

\section{DOI: https://dx.doi.org/10.4314/jasem.v23i7.12}

Copyright: Copyright $\left({ }^{\circ} 2019\right.$ Tefera et al. This is an open access article distributed under the Creative Commons Attribution License (CCL), which permits unrestricted use, distribution, and reproduction in any medium, provided the original work is properly cited.

Dates: Received: 19 May 2019; Revised: 26 June 2019; Accepted 12 July 2019

Keywords: Drought, Vulnerability, Risk, Spatial-pattern

According to Unicef, (2011) drought risk is considered as a potential disaster loss that could occur to a particular community caused by drought over some specified future time period. It is the result of the interaction between drought hazards and the vulnerability of the people, ecosystems, and economies exposed to the hazard (UNESCO, 2016). Drought risk comprises different types of potential losses, which are often difficult to quantify. However, detailed drought assessment and quantification can is possible by using the drought hazard information and the patterns of socio-economic developments (UNISDR, 2009). Drought risk assessment is used to inspect the risk levels to the exposed people, property, services, livelihoods and the environment to drought, by integrating the potential drought hazards and existing conditions of drought vulnerability (Unicef, 2011). Drought hazard, one of the two determinant factors of drought risk, is a potentially damaging physical phenomenon that may cause the loss of life or injury, property damage, social and economic disruption or environmental degradation. Hence, it can be characterized by its location, intensity, frequency and probability (UNESCO, 2014; Unicef, 2011;
UNISDR, 2009, 2015). Vulnerability, on the other hand, refers to the tendency to be adversely affected by any change in the environment (IPCC, 2014). It is determined by physical, social, economic and environmental factors, with the potential of increasing the communities susceptibility to drought hazard impacts (UNESCO, 2014; Unicef, 2011; UNISDR, 2009, 2015). Vulnerability can also be perceived as a function of dimensions including sensitivity and adaptive capacity (Unicef, 2011; IPCC, 2014; Noble et al., 2014). These three dimensions, thus, need to be considered in any vulnerability assessment (Liu et al., 2013; Noble et al., 2014). Sensitivity refers the degree to which a system, individuals, families or community will respond to the exposed change in climatic conditions (Adger et al., 2007; Liu, et al., 2013). Whereas adaptive capacity refers to the ability or potential of individual, family, community, or a system to adjust to changes and respond successfully (Adger et al., 2007; IPCC, 2014). It is the capacity to tolerate and deal with emerging changes out of the expected normal condition (Folke, 2006). Studies (Adger et al., 2007; Noble et al., 2014) show that adaptive capacity is influenced by the resources 
available for adaptation, and by the ability or capacity of that system or community to use these resources effectively in the pursuit of adaptation. Presence of high adaptive capacity means that the exposed community, system or family is resilient and can adapt and maintain the desired state of balance in the transformation when the current state is on shaky ground (Folke, 2006). So far, various attempts have been made to understand the local climate variability and to reliably forecast future drought impacts in the Tigray region (Abrha and Simhadri, 2015; Gedif et al., 2014; Abraha 2013; Gebrehiwot and VanDerVeen, 2013). Drought risk assessment attempts, as part of drought management, have also been made by using GIS and Remote Sensing based data and techniques which primarily implemented Normalized Difference Vegetation Index (NDVI) and Vegetation Condition Index (VCI) as tools of analyses (Gedif et al., 2014). In a much-related study by Teklehaymanot, (2014), drought risk monitoring portal design and development was carried out with more emphasis on installing easily accessible and understandable geospatial data to supplement decision makers with the required drought-related information. Policy level evaluation of drought mitigation was also conducted by Sara, (2010) and revealed that government policy interventions have helped improve the resilience of the society through job creation and natural resource conservation activities.

Even though robust efforts and worldwide improvements in drought management are helping towards avoiding causalities like in the past 100 years, it is stated in UNISDR, (2011) that the social and economic impacts of drought are still inexplicably concentrated on poor rural households that depend on rain-fed subsistence agriculture. Given the fact that drought impacts are not systematically recorded, developing drought risk model at the global scale may not be an easy task. Hence, it is recommended that building such a model at local, regional and global levels is imperative to increase the visibility of the risk and identification of appropriate drought risk management options. Considering the drought history of the study area, this study was initiated with a primary objective of assessing the spatial extent and pattern of drought hazards, drought vulnerability and drought risks in all of the 34 districts. SPEI was the main analyses tool used to assess the drought occurrence in each district. The drought occurrence information was, used to generate drought hazard information which was further integrated with drought vulnerability assessment results to develop a comprehensive and spatially explicit drought risk model for the study area.

\section{MATERIALS AND METHODS}

Study area: The study area, Tigray Regional State, is one of the national regional states of Ethiopia located in the northernmost part of the country (Gebrehiwot et al., 2011). The region is bordered by Eritrea to the north, Sudan to the west, and with Ethiopian regions of Amhara and Afar to the south and the east respectively (FDRE, 2016). The state is structured into five administrative zones (see Figure 1). The administrative zones are divided into 34 districts locally called "Wereda". The areal coverage of the region is estimated to be 53,638 square kilometres with a total population of 5,484,405 (CSA 2007 census projected for 2017).

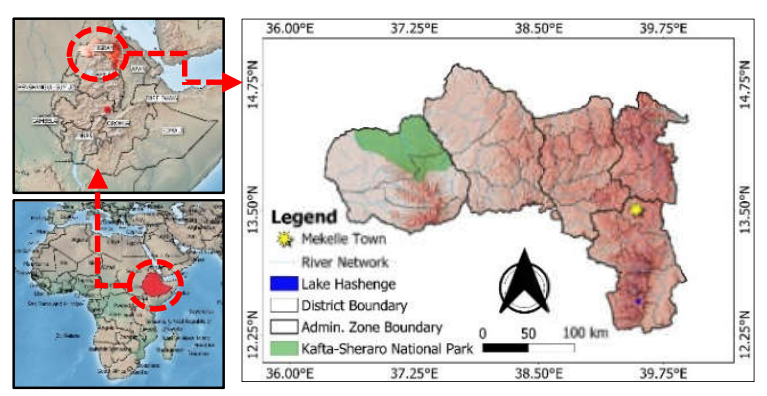

Fig 1: Map of the study area

The average rainfall varies from about $200 \mathrm{~mm}$ in the northeast lowlands to over $1000 \mathrm{~mm}$ in the south-west highlands. Moreover, the average annual temperature varies from less than $7.5^{\circ} \mathrm{C}$ in the highlands, with greater than 3500 meters above sea level, to greater than $27^{\circ} \mathrm{C}$ in the eastern lowlands (Abraha, 2013).

Climate data: In this research Gridded Climatic Research Unit (CRU) Time-series (TS) dataset version 4.01 (Temperature and Precipitation data), with a $0.5^{0}$ $\mathrm{x} 0.5^{0}$ spatial resolution and 1901 to 2016 temporal coverage was used to calculate the SPEI of the study area. The CRU TS4.01 dataset is a monthly gridded field data based on monthly observational data calculated from daily or sub-daily data by National Meteorological Services and other external agents (Harris and Jones, 2017). This dataset was chosen for its wider application in various studies (Guo et al., 2019; Ahmed et al., 2019; Herrera-Soto et al., 2018; Shi et al., 2017; Los, 2015), and its spatial and temporal coverage. Accordingly, the climate data was collected on twelve systematically selected stations on a monthly basis and used for analyses of drought hazard.

Socio-economic data: Data on vulnerability indicators for each of the 34 districts were collected from the National Disaster Risk Management Commission Wereda Disaster Risk Profile database. This project 
used both primary and secondary data sources. The primary data included data collected using three kinds of study tools; namely Focus Group Discussion, Key Informant Interview and Household Sample Survey. The secondary data sources used included topographic and Geomorphic information (IFPRI Atlas), meteorological information (NMA), demographic information (Census, CSA), access to electricity (ELPA), access to health facilities (Ministry of Health), frequency of disaster occurrence (Risk Baseline surveys) and livelihood sources (LIU). The details of data collection and analyses techniques are well documented in (DRM and FSS, 2014; NDRMC, 2015).

Lastly, after the validation, the WDRPs were uploaded on the official website (http://profile.dppc.gov.et) to be viewed and accessed by all users worldwide. Moreover, additional information was collected from the Tigray Region Bureau of Agriculture, Tigray Region Bureau of Water Resource and Energy, Tigray Region Bureau of Education and Ethiopian Electric Utility/Northern Region. The collected data was then categorized as indicators and grouped under two major sections; as drought sensitivity indicators and drought adaptive capacity indicators. The indicators under sensitivity were further split into four dimensions of Physical Sensitivity, Environmental Sensitivity, Economic Sensitivity and Social Sensitivity. Similarly, the indicators identified under drought adaptive capacity were split under Physical Capital, Natural Capital, Financial Capital and Social Capital. The details of the indicators are shown in Table 1.

Table 1: List of dimensions and their corresponding indicators used in obtaining drought adaptive capacity and drought sensitivity index

\begin{tabular}{|c|c|c|}
\hline & Dimensions & Indicators \\
\hline \multirow{13}{*}{ 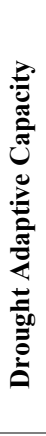 } & \multirow{5}{*}{ Physical capital } & Access to electricity \\
\hline & & Access to agricultural extension services \\
\hline & & Access to sanitation (toilet and latrine) \\
\hline & & Access to veterinary services \\
\hline & & Per cent of energized districts \\
\hline & \multirow{3}{*}{ Natural capital } & Access to drinking water \\
\hline & & Long-term average vegetation cover \\
\hline & & Population to water facility ratio \\
\hline & \multirow{2}{*}{ Financial capital } & Access to credit \\
\hline & & Livestock population density \\
\hline & \multirow{3}{*}{ Social capital } & Community awareness towards disaster risk management \\
\hline & & Presence of community-based organizations \\
\hline & & Level of social cooperation \\
\hline \multirow{13}{*}{ 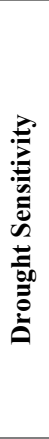 } & \multirow{3}{*}{ Physical sensitivity } & Number of households with access to road \\
\hline & & Average time to nearest paved road \\
\hline & & Distance to nearest urban centre \\
\hline & Environmental sensitivity & Access to pesticides \\
\hline & \multirow{6}{*}{ Economic sensitivity } & Access to improved seeds \\
\hline & & Access to fertilizers (chemical and natural) \\
\hline & & Access to market \\
\hline & & Number of available NGOs \\
\hline & & Number of economic activities (income options) \\
\hline & & Number of beneficiaries by household \\
\hline & \multirow{3}{*}{ Social sensitivity } & Literacy level (above 7 years old) in \% \\
\hline & & Health facility to population ratio \\
\hline & & Human pop density \\
\hline
\end{tabular}

Data analyses: Drought Vulnerability Index (DVI) was used to determine the vulnerability status of the study area. The index of two vulnerability dimensions, sensitivity and adaptive capacity dim, were computed first. The indicators for each of the vulnerability dimension with their detailed descriptions and measurements were identified based on literature (Blauhut et al., 2016; Liu et al., 2013; Lockwood et al., 2015; UNDP, 2011; Unicef, 2011). Afterwards, a method developed by Patnaik and Narayanan, (2009) was used to develop the index for vulnerability dimensions, including sensitivity and adaptive capacity.
$D I_{x}=\frac{\left[\sum_{i=1}^{n}\left(A I_{i}\right)^{n}\right]^{1 / n}}{n} \quad A I=\frac{\sum X_{i}}{n}$

Where, $D I_{x}$ is dimension index of group $\mathrm{x}, \mathrm{AI}$ is an average index of a group $\mathrm{x}, \mathrm{n}$ is number of indicators classified under each group.

The vulnerability index equation used in this study considered the functional relationship concept used for developing risk assessment equation in UNDP, (2011). The concept is that; drought adaptive capacity has an inverse functional relationship with 
vulnerability. Based on this concept, an equation, shown below, was derived and was used to analyse the vulnerability index for the study area.

$V I=\frac{S I}{A C I}$

Where, VI is vulnerability index, SI is sensitivity index and ACI adaptive capacity index.

According to Zhang and Zhang, (2016), drought hazard is defined as the result of frequency and intensity of the drought events. High frequency and intensity of drought in an area indicates the potential for the availability of higher future drought occurrence probabilities. In this study, SPEI was used to quantify the drought intensity and magnitude for the period 1901 to 2016. The probability of occurrence was calculated by using poison probability distribution function.

$$
P_{t}(r)=\frac{(\mu t)^{r}}{r !} e^{-\mu t}
$$

Where, $\mathrm{P}_{\mathrm{t}}(\mathrm{r})$ is poison probability function, $\mathrm{r}$ is the number of occurrences the probability is calculated for, $t$ is the time period of interest and $\mu$ is the counting rate, $\mathrm{m}$ is number of years on record, $\mathrm{n}$ is number of recorded occurrences of the event being considered.

Each drought severity class were given weight (i.e. starting with 1 for mild drought up to 4 for extreme drought in order of their severity). The probability of occurrence was then categorized into four ratings using Jenkins natural break method as indicated in Table 2. Jenks natural break method is a data clustering method that defines the best arrangement of values into different classes based on natural groupings inherent in the data itself (Kamali et al., 2017).

The drought hazard index (DHI) was then calculated by combining drought severity (weighted) and drought occurrence probability (rated).

$$
\mathrm{DHI}=(\mathrm{W} 1 \times \mathrm{R} 1)+(\mathrm{W} 2 \times \mathrm{R} 2)+(\mathrm{W} 3 \times \mathrm{R} 3)+(\mathrm{W} 4 \times \mathrm{R} 4)
$$

Where, DHI is drought hazard index, W1, W2, W3 and W4 are weight values representing mild, moderate, severe and extreme droughts (numbered 1 to 4 ) respectively; $\mathrm{R} 1, \mathrm{R} 2, \mathrm{R} 3$, and $\mathrm{R} 4$ represent the rate values (from 1 to 4 ) based on the probability of occurrence obtained from the Jenks natural break method (Kamali et al., 2017).

\begin{tabular}{|c|c|c|c|c|}
\hline Drought class & SPEI value & Weight & $\%$ of occurrence probability & Rating \\
\hline \multirow{4}{*}{ Mild drought } & \multirow{4}{*}{0 to -0.99} & \multirow{4}{*}{$\mathrm{W}_{1}=1$} & $\operatorname{Pr} \leq 6.06$ & 1 \\
\hline & & & $6.13 \leq \mathrm{pr} \leq 6.29$ & 2 \\
\hline & & & $6.36 \leq \mathrm{pr} \leq 6.62$ & 3 \\
\hline & & & $\operatorname{Pr} \geq 7.13$ & 4 \\
\hline \multirow{4}{*}{ Moderate drought } & \multirow{4}{*}{-1.0 to -1.49} & \multirow{4}{*}{$\mathrm{W}_{2}=2$} & $\operatorname{Pr} \leq 11.93$ & 1 \\
\hline & & & $12.51 \leq \mathrm{pr} \leq 12.91$ & 2 \\
\hline & & & $13.17 \leq \mathrm{pr} \leq 13.95$ & 3 \\
\hline & & & $\operatorname{Pr} \geq 17.54$ & 4 \\
\hline \multirow{4}{*}{ Severe drought } & \multirow{4}{*}{-1.5 to -1.99} & \multirow{4}{*}{$\mathrm{W}_{3}=3$} & $\operatorname{Pr} \leq 13.95$ & 1 \\
\hline & & & $14.89 \leq \mathrm{pr} \leq 16.06$ & 2 \\
\hline & & & $17.54 \leq \mathrm{pr} \leq 19.53$ & 3 \\
\hline & & & $\operatorname{Pr} \geq 22.40$ & 4 \\
\hline \multirow{4}{*}{ Extreme drought } & \multirow{4}{*}{$\leq-2$} & \multirow{4}{*}{$\mathrm{W}_{4}=4$} & $\operatorname{Pr} \leq 19.53$ & 1 \\
\hline & & & $22.40 \leq \mathrm{pr} \leq 23.24$ & 2 \\
\hline & & & $27.07 \leq \mathrm{pr} \leq 28.72$ & 3 \\
\hline & & & $\operatorname{Pr} \geq 36.79$ & 4 \\
\hline
\end{tabular}

Table 2: Weights and ratings assigned to each drought severity classes and occurrence probabilities respectively

Lastly, drought risk index (DRI) was developed for the study area by multiplying drought hazard index (DHI) with drought vulnerability index (DVI).

$D R I=D H I \times D V I$

Jenkins natural break method was then used to characterize the severity levels of drought risk in the study area. Finally, the spatial pattern of drought hazard, drought vulnerability and drought risk were tested for randomness using Moran's I (spatial autocorrelation) based on the final drought risk output. Moreover, One-way ANOVA was used to test for variation in drought hazard, drought vulnerability and drought risks between districts.

\section{RESULT AND DISCUSSION}

Assessment of drought vulnerability: Drought vulnerability being the result of drought sensitivity (Figure 2a) and drought adaptive capacity (Figure 2b), 
it is indicated in Table 2 that about $17.6 \%, 14.7 \%$ and $3.5 \%$ of the districts were categorized under moderate, high and very high vulnerability classes. However, low and very low drought vulnerability conditions were observed in $44.1 \%$ altogether. Spatially, very high drought vulnerability was distributed in the southern parts of western and north-western zones, and western parts of the southern zone (Figure 3a). Additionally, districts at the northern tip of the central and eastern zones were also characterized by very high drought vulnerability. About $32.4 \%$ of districts were largely categorized under high and moderate severity classes. Hence, according to Rajsekhar et al., (2015), the districts which are characterized with high vulnerability indices are considered as highly prone to drought caused damages. Moreover, the spatial autocorrelation analyses result (Table 4) for drought sensitivity and drought adaptive capacity indicated that given the $\mathrm{z}$-score of 0.4 and -0.02 , the pattern for both indices were random at $\mathrm{p}<0.05$ significance level. Similarly, the spatial pattern of drought vulnerability doesn't appear to be significantly different than random (z-score $=0.21, \mathrm{p}<0.05)$. Furthermore, the results of the one-way ANOVA test indicated no significant variation in all indices between districts at $\mathrm{p}<0.05$.

Assessment of drought hazard: A 12-month SPEI has been used to assess the long-term drought conditions at the district level. It was based on this 12-month time scale that the drought hazard assessment was made. The test for spatial autocorrelation showed a clustered spatial pattern of drought hazard in the study area. However, differences were evident in the per cent of districts categorized under different hazard classes (see Table 3). However, in this study the presence of any drought hazard variation between districts has tested negative; $\mathrm{F}(4,29)=0.74, \mathrm{p}=0.57$ at $\mathrm{p}<0.05$.

Table 3: Per cent (\%) of districts under different severity classes, by index. Values in each column represent the per cent of districts classified under "Very Low", "Low", "Moderate", "High" and "Very High" severity classes of their corresponding index

\begin{tabular}{llllll}
\hline Class & DSI & DACI & DVI & DHI & DRI \\
\hline Very Low & 20.6 & 2.9 & 17.6 & 20.6 & 20.6 \\
\hline Low & 11.8 & 2.9 & 26.5 & 17.6 & 20.6 \\
\hline Moderate & 38.2 & 32.4 & 17.6 & 17.6 & 14.7 \\
\hline High & 11.8 & 47.1 & 14.7 & 17.6 & 23.5 \\
\hline Very High & 17.6 & 14.7 & 23.5 & 26.5 & 20.6
\end{tabular}

"DSI"_drought severity Index; "DACI"_Drought Adaptive Capacity Index; "DVI"_Drought Vulnerability Index, "DHI”_Drought Hazard Index; "DRI" _ Drought Risk Index

Table 4: Spatial autocorrelation and One-way ANOVA summary table for drought severity, drought adaptive capacity, drought vulnerability, and drought hazard and drought risk

\begin{tabular}{llllll}
\hline \multirow{2}{*}{ Index } & \multicolumn{2}{l}{ Moran's Index } & \multicolumn{3}{c}{ ANOVA } \\
\cline { 3 - 6 } & Z-score & p-value & Pattern & F-value & p-value \\
\hline DSI & 0.40 & 0.69 & Random & 1.208 & 0.329 \\
\hline DACI & -0.02 & 0.98 & Random & 0.598 & 0.667 \\
\hline DVI & 0.21 & 0.83 & Random & 0.961 & 0.444 \\
\hline DHI & 4.35 & 0.0001 & Clustered & 0.746 & 0.569 \\
\hline DRI & 4.72 & 0.0001 & Clustered & 1.385 & 0.263 \\
\hline
\end{tabular}

"DSI"_drought severity Index; "DACI"_Drought Adaptive Capacity Index; "DVI"_Drought Vulnerability Index, "DHI" _Drought Hazard Index; "DRI"_Drought Risk Index

The results also indicated that more than half of the districts in the study area $(55.9 \%)$ are characterized by very low and low levels of drought hazard.

The remaining $44.1 \%$ accounted for moderate to high and very high drought hazard levels. Looking at the spatial distribution of drought hazard, it is clearly indicated in Figure $3 \mathrm{~b}$ that above average drought hazards are most common in the western, eastern and southern zones. Chemonics International, (2015) and Gebrehiwot et al., (2011) were able to capture high drought hazard levels in eastern and southern zones. However, this study has identified the western zone along with the already identified eastern and southern zones as high drought hazard areas. Contrarily, central and north-western zones are designated as low drought hazard areas.

Assessment of drought risk: Drought risk assessment, computed by multiplying meteorological drought hazard and socio-economic drought vulnerability dimensions, is crucial in identifying drought risk levels and make comparisons among districts for management prioritization (Dabanli, 2018). Shahid and Behrawan, (2008) used the natural break method to classify drought risk values into four levels and produced risk maps accordingly. In this study, drought risk index values were also classified using Jenkin's natural method, but the number of classes was set to five levels. 

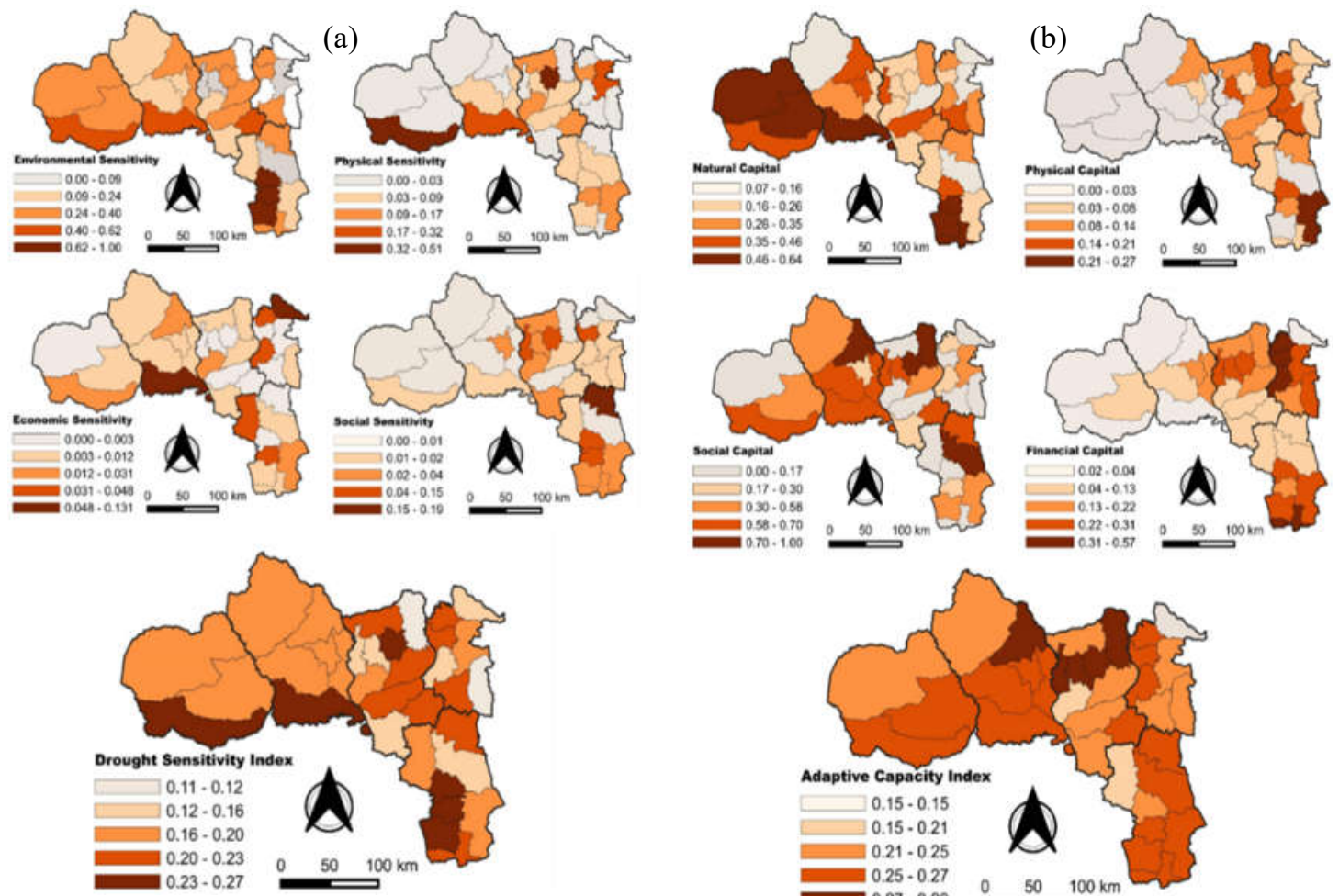

Fig 2: Drought sensitivity (a) and drought adaptive capacity (b) indices and their corresponding dimensions

In Figure $3 \mathrm{c}$ the spatial distribution of above average drought risk accounting for $44 \%$ are evident in most districts of the western, eastern and southern zones. However, below average drought risks covered about $55.9 \%$ of districts mostly situated in the central and north-western zones. The spatial distribution indicated in Figure 3c agreed with the Moran's I test result for autocorrelation which indicated the clustered pattern of the district-based drought risks.
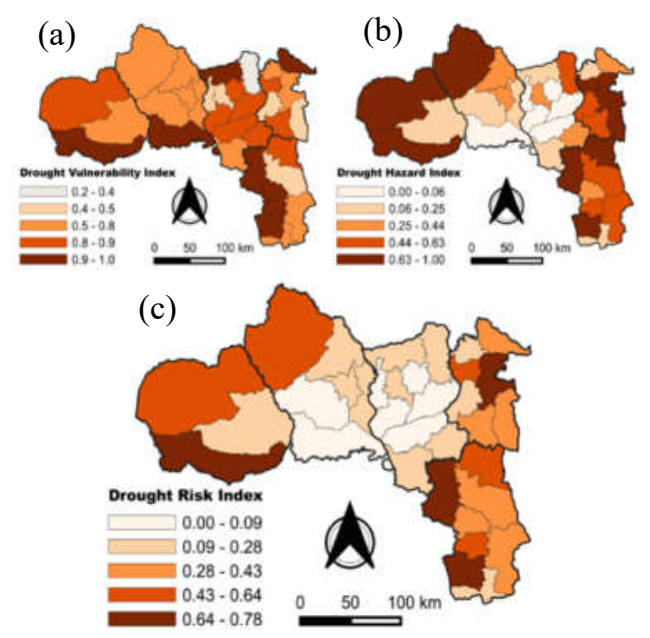

Fig 3: Map of (a) drought vulnerability index, (b) drought hazard index and (c) drought risk index
The results indicate that the district-based drought risks are clustered at $p<0.05$ level of significance. Hence, according to these findings, the western, eastern and southern zones are designated as high drought risk areas, while central and north-western zones are designated as low drought risk areas. The study has also revealed no statistically significant variation in drought risk between districts at $\mathrm{p}<0.05$.

Conclusion: This study found no evidence showing any significant variation in drought sensitivity, drought adaptive capacity, drought vulnerability, drought hazard and drought risk between districts in the study area. The study has also revealed the clustered nature of drought hazard and drought risk in the study area. Hence, most districts in the western, eastern and southern zones were categorized as high drought risk areas. Generally, the study has demonstrated the importance of the integration of socioeconomic and climate data to generate spatially explicit drought risk information. The study recommends the use of detailed socioeconomic information and high-resolution long-term climate data for better drought risk assessment results.

Acknowledgements: The authors wish to acknowledge the financial support by the Pan African University (PAU), African Union (AU), Addis Ababa, Ethiopia. The authors would also like to extend their 
appreciation to the anonymous reviewers as well as to everyone who contributed to the success of this study.

\section{REFERENCES}

Abraha, ME (2013). Assessment of Drought Early Warning in Ethiopia: A Comparison of WRSI by Surface Energy Balance and Soil Water Balance. University of Twente, Netherlands.

Abrha, MG; Simhadri, S (2015). Local Climate Trends and Farmers' Perceptions in Southern. Int. J. Environ. Sustain. 4(3): 11-28.

Adger, WN; Agrawala, S; Mirza, MM; Conde, C; O'Brien, K; Pulhin, J; Smit, B (2007). Assessment of Adaptation Practices, Options, Constraints and Capacity. Climate Change 2007: Impacts, Adaptation and Vulnerability. Cambridge Uni. Press. 717-743.

Ahmed, K; Shahid, S; Wang, X; Nawaz, N; Najeebullah, K (2019). Evaluation of Gridded Precipitation Datasets over Arid Regions of Pakistan. Water. 11(2): 210.

Asheber, S (2010). Mitigating Drought : Policy Impact Evaluation A Case of Tigray Region, Ethiopia Mitigating Drought : Policy Impact Evaluation A Case of Tigray Region, Ethiopia. MSc Thesis, University of Twente Faculty of Geo-Information and Earth Observation (ITC), The Netherlands.

Blauhut, V; Stahl, K; Stagge, JH; Tallaksen, LM; Stefano, L; De; Vogt, J (2016). Estimating Drought Risk Across Europe from Reported Drought Impacts, Drought Indices, and Vulnerability Factors. Hydrol. Earth System Sci. 20(7): 2779-2800.

Chemonics International (2015). Climate Variability and Change in Ethiopia: Summary of Findings. Washington, DC.

Dabanli, I (2018). Drought hazard, vulnerability, and risk assessment in Turkey. Arab. J. Geosci. 11(18): 538 .

DRM; FSS (2014). Wereda Disaster Risk Profiling: A Methodological Note.

FDRE (2016). Ethiopian Government Portal: Tigray regional state. Retrieved October 13, 2017, from http://www.ethiopia.gov.et/tigray-regional-state.

Folke, C (2006). Resilience: The emergence of a perspective for social-ecological systems analyses. Global Environ. Change. 16(3): 253267.

Gebrehiwot, T; VanDerVeen, A; Maathuis, B (2011). Spatial and temporal assessment of drought in the Northern highlands of Ethiopia. Int.l J. Appl. Earth Observ. and Geoinform. 13(3): 309-321.

Gebrehiwot, T; VanDerVeen, A (2013). Assessing the evidence of climate variability in the northern part of Ethiopia. J. Develop. Agric. Econ. 5(3): 104119.

Gedif, B; Hadish, L; Addisu, S; Suryabhagavan KV (2014). Drought risk assessment using remote sensing and GIS techniques. Arab. J. Geosci. 7(1): 35-53.

Guo, S; Ge, X; Zou, Y; Zhou, Y; Wang, T; Zong, S (2019). Projecting the Potential Global Distribution of Carpomya vesuviana (Diptera: Tephritidae), Considering Climate Change and Irrigation Patterns. Forests. 10(4): 355.

Harris, IC; Jones, P (2017). Climatic Research Unit (CRU) Time-Series (TS) Version 4.01 0f HighResolution Gridded Data Of Month-by-Month Variation in Climate (Jan. 1901- Dec. 2016). University of East Anglia Climatic Research Unit, Centre for Environmental Data Analysis, England.

Herrera-Soto, G; Gonzalez-Casares, M; PompaGarcía, M; Camarero, J; Solis-Moreno, R (2018). Growth of Pinus cembroides Zucc. in Response to Hydroclimatic Variability in Four Sites Forming the Species Latitudinal and Longitudinal Distribution Limits. Forests. 9(7): 440.

IPCC (2014). Annex II: Glossary. In: Cli- mate Change 2014: Synthesis Report. Contribution of Working Groups I, II and III to the Fifth Assessment Report of the Intergovernmental Panel on Climate Change. Geneva, Switzerland. p.117-130.

Kamali, B; Kouchi, DH; Yang, H; Abbaspour, KC (2017). Multilevel drought hazard assessment under climate change scenarios in semi-arid regions-a case study of the karkheh river basin in Iran. Water. 9(4): 241.

Liu, X; Wang, Y; Peng, J; Braimoh, AK; Yin, H (2013). Assessing Vulnerability to Drought based on Exposure, Sensitivity and Adaptive Capacity: A Case Study in Middle Inner Mongolia of China. 
Chinese Geog. Sci. 23(1): 13-25.

Lockwood, M; Raymond, CM; Oczkowski, E; Morrison, M (2015). Measuring the Dimensions of Adaptive Capacity: A Psychometric Approach. Ecol. Soci. 20(1): 37.

Los, SO (2015). Testing gridded land precipitation data and precipitation and runoff reanalyses (1982-2010) between $45^{\circ} \mathrm{S}$ and $45^{\circ} \mathrm{N}$ with normalised difference vegetation index data. Hydrol. Earth System Sci. 19(4): 1713-1725.

NDRMC (2015). Wereda Disaster Risk Profiling Validation Manual. Retrieved January 15, 2018 from http://profile.dppc.gov.et.

Noble, IR; Huq, S; Anokhin, YA; Carmin, J; Goudou, D; Lansigan, FP; Villamizar, A (2014). Adaptation Needs and Options. Cambridge Uni. Press. 833-868.

Patnaik, U; Narayanan, K (2009). Vulnerability and Climate Change: An Analysis of the Eastern Coastal Districts of India. Indian Institute of Technology, Bombay.

Rajsekhar, D; Singh, VP; \& Mishra, AK (2015). Integrated drought causality, hazard, and vulnerability assessment for future socioeconomic scenarios: An information theory perspective. J. Geophys. Res. Atmos. 120(13): 6346-6378.

Shahid, S; Behrawan, H (2008). Drought risk assessment in the western part of Bangladesh. Nat. Hazards. 46(3): 391-413.
Shi, H; Li, T; Wei, J (2017). Evaluation of the gridded CRU TS precipitation dataset with the point raingauge records over the Three-River Headwaters Region. J. Hydrol. 548: 322-332.

Teklehaymanot, A (2014). A GeoPortal Design for Drought Risk Monitoring in Tigray Ethiopia. Int. J. Sustain. Develop. Res. 2(1): 1-5.

UNDP (2011). Mainstreaming Drought Risk Management - A Primer. Nairobi, Kenya.

UNESCO (2014). Glossary of Basic Terminology on Disaster Risk Reduction. Bangkok.

UNESCO (2016). Drought Risk Management - A strategic approach. Paris, France.

Unicef (2011). VCA Tool \& Guidelines: Assessing Hazard, Risk \& Vulnerability. Kenya.

UNISDR (2009). UNISDR-Terminology on Disaster Risk Reduction. Geneva, Switzerland.

UNISDR (2011). 2011 Global Assessment Report on Disaster Risk Reduction: Revealing Risk, Redefining Development_Summary and Main Findings. Oxford, UK.

UNISDR (2015). Proposed Updated Terminology on Disaster Risk Reduction: A Technical Review.

Zhang, Q; Zhang, J (2016). Drought hazard assessment in typical corn cultivated areas of China at present and potential climate change. Nat. Hazards. 81(2): 1323-1331. 